\title{
Science in Society: Re-evaluating the Deficit Model of Public Attitudes
}

\begin{abstract}
The 'deficit model' of public attitudes towards science has led to controversy over the role of scientific knowledge in explaining lay people's attitudes towards science. The most sustained critique has come from what we refer to as the 'contextualist' perspective. In this view, people's understanding of the ways in which science is embedded within wider political, economic and regulatory settings is fundamental for explaining their attitudes towards science. Most work adopting this perspective has relied on qualitative case studies as empirical evidence. In this paper we challenge the de facto orthodoxy that has connected the deficit model and contextualist perspectives with quantitative and qualitative research methods respectively. We simultaneously test hypotheses from both theoretical approaches using quantitative methodology. We use data from the 1996 British Social Attitudes Survey to investigate the interacting effects of different domains of scientific and contextual knowledge on public attitudes toward science. The results point to the clear importance of knowledge as a determinant of attitudes toward science. However, in contrast to the rather simplistic deficit model that has traditionally characterised discussions of this relationship, this analysis highlights the complex and interacting nature of the knowledge-attitude interface.
\end{abstract}




\section{Science in Society: Re-evaluating the Deficit Model of Public Attitudes ${ }^{1}$}

\section{THE DEFICIT MODEL AND ITS CRITICS}

The field of study known as 'public understanding of science' stands today at something of a crossroads (Miller 2001). In the fifteen years or so since the publication of the Bodmer report by the Royal Society (Bodmer 1985), the loose assemblage of interdisciplinary approaches that have been applied to the field has produced much in the way of practical educational initiatives such as 'Science, Technology and Engineering Week' in the UK and 'Project 2061' in the United States. Many other science popularisation initiatives in the UK have been funded through the Committee for Public Understanding of Science (COPUS). Scholarship has also flourished, with much funding directed at academic research into science communication and public attitudes towards science and technology.

A major aim of COPUS was not only to popularise science, but also to enhance the 'scientific literacy' of the British public. The Bodmer report was commissioned in the belief that the public's interest in and support for science and scientists was waning. At the same time, scientists themselves had retreated from public debate to an alarming degree. The report suggested not only that scientists now had a duty to go out and communicate the benefits of science to a wider public, but also that a more 'scientifically literate' public would be more supportive of scientific research programs and more enthusiastic about technological innovations. This would, of course, be a rather happy outcome for the scientific research community.

A scientifically literate citizenry is also one that can effectively participate in public debates about science and hold government to account over the speed and direction of science policy. From this normative perspective, in modern democratic societies, citizens need to have sufficient levels of accurate information on which to base their assessments of policy alternatives in order that their policy preferences best reflect their own self or group 
interests (Converse 1964, Delli-Carpini and Keeter 1996). As scientific and technological innovations become increasingly central to the functioning of modern societies and to the daily lives of individual citizens, the argument goes, so the importance of technical and scientific knowledge within the mass public is concomitantly augmented.

There is little doubt, however, that one of the primary motives underlying recent government and business initiatives to increase public 'understanding' of science is what Nelkin (1995) calls 'selling science' (see for example Office of Science and Technology and the Wellcome Trust 2001). Implicit or explicit, in this programmatic agenda is the claim that 'to know science is to love it'. That is to say, the more one knows about science, the more favourable one's attitude towards it will be. Regrettably, from this point of view at least, publics both in Europe and in the United States appear to possess depressingly low levels of scientific knowledge. Jon Miller conceptualises 'civic scientific literacy' as comprising three related dimensions: 'a vocabulary of basic scientific constructs sufficient to read competing views in a newspaper or magazine...an understanding of the process or nature of scientific inquiry...some level of understanding of the impact of science and technology on individuals and on society' (Miller 1998). While Miller's concept is by no means an uncontested one, on his definition not more than one quarter of the European and US publics qualify as scientifically literate. Moreover, this situation has hardly changed since systematic measurements first began in the late 1950s, despite the best efforts of governments and educators alike to popularise science and make it more accessible to ordinary citizens during the intervening years. Withey (1959) found that In 1957 only about 10 percent of Americans correctly defined science as having to do with the concepts of controlled experimentation, theory and systematic variation. Fifteen years later, when the U.S. National Science Foundation (NSF) initiated its Science Indicators survey series, the proportion was unchanged (Gregory and Miller 1998). In 1988, Durant, Evans and Thomas (1989) reported that only 17 percent of the British public spontaneously referred to experimentation and/or theory testing when asked the question: "what does it mean to study something 
scientifically?' When the same question was asked nearly a decade later, in the 1996 British Social Attitudes survey (Jowell, Curtice, Park, Brook, Thomson and Bryson 1997), the proportion remained statistically unchanged at 18 percent. The picture for what might be considered 'factual' or 'textbook' scientific knowledge is similar. For instance, Durant, Evans and Thomas (1989) report that in 1988 only 34 percent of the British public knew that the earth goes around the sun once a year and only 28 percent knew that antibiotics kill bacteria but not viruses (see appendix for more factual knowledge questions from this survey). In the USA, respondents faced with the same questions fared similarly to their British counterparts, with 46 and 25 percent providing the correct answer respectively.

Against this backdrop of widespread scientific 'ignorance' amongst lay publics, there has been, over the past few decades, rising public scepticism about the benefits of scientific and technological innovation and a diminishing conviction that scientific progress is coterminous with social progress (Hargreaves 2000, Touraine 1985). In Britain, this view motivated a major public inquiry into the relationship between science and society by the House of Lords Select Committee on Science and Technology (2000) which suggested that 'society's relationship with science is in a critical phase' characterised by 'public unease, mistrust and occasional outright hostility'. Unease of this kind has been evident in public controversies a number of years, concerning, for example, the real and potential dangers of DDT in the early 1960s, nuclear power in the 1970s and 1980s and, more recently, crises in public confidence in farming and food technologies following the BSE scandal in Britain in the 1990s. Typifying this state of affairs at present is gene technology. While held out by some as promising almost limitless future benefits for society, optimism about these prospects in Europe has steadily declined since the beginning of the 1990s (Gaskell, Allum, Wagner, Hviid Nielsen, Jelsoe, Kohring and Bauer 2001). The scientific community, along with governments and industry, all now recognise that a sufficiently hostile public and media can 
seriously constrain or even veto a contentious research program (Miller, Pardo and Niwa 1997).

The assumption that it is a lack of public understanding or knowledge that has led to the present climate of scepticism toward science underpins what has come to be known as the 'deficit model' (Layton, Jenkins, McGill and Davey 1993, Wynne 1991, Ziman 1991). In this formulation, it is the public that are assumed to be 'deficient', while science is 'sufficient' (Gross 1994). The public's doubts about the value of scientific progress or fears about new or unfamiliar innovations, such as genetically modified organisms or microwave ovens, are due to ignorance of the science behind them. Lacking a proper understanding of the relevant facts, people fall back on mystical beliefs and irrational fears of the unknown. If one accepts this hypothesis, the obvious implication for science policy is that public information campaigns should be instigated to remedy the public's disenchantment with science. Whilst the deficit model, as we shall refer to it here, is to some extent a simplification, or even something of a 'straw man', it quite evidently underlies many programmatic statements from the scientific community when the misplaced fears of a scientifically illiterate public and mass media are bemoaned (Evans and Durant 1995). And the simple logic of the deficit model is supported by a good deal of cross-national empirical evidence for a robust but not especially strong positive correlation between 'textbook' scientific knowledge and favourability of attitude toward science (e.g. Bauer, Durant and Evans 1994, Evans and Durant 1995, Gaskell, Allum, Wagner, Hviid Nielsen, Jelsoe, Kohring and Bauer 2001, Grimston 1994, McBeth and Oakes 1996, Miller, Pardo and Niwa 1997, Sturgis and Allum 2000, Sturgis and Allum 2001).

Unsurprisingly, given its normative and epistemological implications, the deficit model has come in for sustained criticism on a number of grounds. Firstly, the assumption that socalled 'irrational' fears of lay publics are based on lack of scientific understanding has been strongly challenged by a number of commentators. Douglas and Wildavsky (1982), for example, have argued that people's fears about new technologies are functional in that they 
provide a basis for maintaining cultural associations. In other words, people select risks to worry about according to the norms of their social milieu rather than responding to supposedly more 'objective' hazards. Others have shown that perceptions of technological risks are related to certain types of worldview (Slovic and Peters 1998) or the holding of certain core beliefs and values such as environmentalism. In none of these conceptions is the perception of risk dependent primarily on one's level of scientific understanding.

Another criticism of the deficit model and the way in which it has been approached via quantitative survey research focuses on the selection of appropriate measures of scientific understanding (Hayes and Tariq 2000, Peters 2000). The argument is made that proponents and opponents in scientific controversies are likely to select different domains of knowledge as being relevant or important (Peters 2000). The normative assumptions behind the selection and development of knowledge measures such as those of Withey, Miller, Evans and Durant may not necessarily correspond with those of all protagonists in any given scientific controversy. Peters (2000), for example, criticises some of the knowledge measures used in the 1992 Eurobarometer survey (INRA 1993) as being based on a 'culturally determined idealisation' of what should constitute scientific knowledge. As a result, he argues, the measures present a biased indication of the relative levels of relevant scientific understanding that is dependent on respondents' national and cultural locations. Another recent current of criticism of the deficit model suggests that the effect of scientific knowledge is far outweighed by the influence of social trust on people's perceptions of new and potentially risky technologies (Priest 2001, Priest 2001, Siegrist, Cvetkovich and Roth 2000).

While these criticisms are undoubtedly in many ways valid, they do not, in our view, sufficiently problematise the deficit model to justify scrapping it entirely. Indeed, we find it puzzling that many scholars utilising survey research methods that consistently uncover associations between knowledge of and attitudes towards science, despite controlling for a 
range of other important characteristics such as age, education and social class, often choose to ignore this finding and instead emphasise the other factors that are also influential in the formation of attitudes (Hayes and Tariq 2000, Hayes and Tariq 2001, Priest 2001, Sturgis and Allum 2001). It is quite clear that culture, economic factors, social and political values and worldviews are all important in determining the public's attitude towards science. There is, however, no reason to assume in consequence that scientific knowledge does not have an additional and independent influence, for reasons that are thus far not clearly understood. In fact there is ample reason to consider it quite implausible that the wellinformed and poorly informed citizen go about the business of making up their minds in the same way (Sniderman, Glaser and Griffin 1990).

\section{THE CONTEXTUALIST PERSPECTIVE}

A more trenchant critique is one which suggests the existence of other knowledge domains that influence attitudes towards science and technology in opposite or conflicting ways to factual scientific knowledge. Jasanoff, for example, suggests that what is important for people's understanding of science is not so much the ability to recall large numbers of miscellaneous facts but rather 'a keen appreciation of the places where science and technology articulate smoothly with one's experience of life... and of the trustworthiness of expert claims and institutions' (Jasanoff 2000). Brian Wynne, an incisive critic of the deficit model of PUS, delineates this position further. Criticising survey-based PUS research's overreliance on simple 'textbook' knowledge scales, he suggests that in order to properly capture the range of knowledge domains relevant to lay attitudes towards scientific research programmes 'three elements of public understanding have to be expressly related: the formal contents of scientific knowledge; the methods and processes of science; and its forms of institutional embedding, patronage, organisation and control' (Wynne 1992)

Clearly the implication of what we shall here refer to as the 'contextualist'2 position is that the deficit model considers only the first two of these elements and that, in neglecting the 
different forms of engagement that individuals and groups might have with science in a variety of contexts, PUS research has overstated the importance of the simple linear deficit model. Other knowledges - be it intimate knowledge of working procedures at a nuclear power plant or awareness of the practical political interdependencies between government, industry and scientific institutions - will always be moderating factors. The ways in which people utilise their factual scientific knowledge is contextualised by the circumstances under consideration. As a corollary to this line of argument we can assume that the third element in this formulation will influence public attitudes in ways opposite to or conflicting with the first two elements. If not, then it would appear to be nothing other than a somewhat more elaborated restatement of the deficit model.

In this vein, Steven Yearley highlights public trust in scientific expertise as a key factor in the contextualisation of knowledge of science (Yearley 2000). Trust in expert claims, he argues, is always mediated by knowledge of the institutional arrangements under which expertise is authorised. Claims to expert knowledge are always contestable depending on what one knows of the relevant institutions. For instance, claims made by government experts may be evaluated differently to those made by scientists employed by nongovernmental organisations. At this point, trust becomes the issue. Of course, in making these evaluations, other psychological and social factors come into play: political ideology, personal interests and preferences. Nevertheless, all things being equal, some form of 'institutional knowledge' will serve in this example to contextualise 'factual' scientific knowledge and knowledge of scientific methods when people evaluate the science under consideration.

Wynne and others who have been instrumental in the articulation of the contextualist perspective have argued that a survey-based, quantitative approach cannot shed any useful light on this or other contextualising forms of knowledge. In fact, it would not be an exaggeration to say that one of the central axioms of this perspective seems to be that 
survey-based methods are at best procrustean and at worst fundamentally misleading for understanding lay publics' knowledge of and interactions with science (Wynne 1995). The principal contention is that 'surveys take the respondent out of [their] social context and are intrinsically unable to examine or control analytically for the potentially variable, socially rooted meanings that key terms have for social actors' (Wynne 1995). Methodologically, the contextualist perspective has relied instead on qualitative case studies for empirical support (e.g. Irwin and Wynne 1996, Kerr, Cunningham-Burley and Amos 1998, Michael 1992, Michael 1996). A contextualist theoretical outlook and a quantitative methodological approach are, apparently, incommensurable from this perspective.

This conflation of theory and method - with contextualist perspectives requiring an ideographic/qualitative approach and quantitative/survey based research seen as good only for propounding the deficit model - is, we believe, both an unnecessary and an unhelpful state of affairs. As Einsiedel astutely remarks: 'Contrasting [the deficit model] with the interactive science model ${ }^{3}$ may have analytical value, but one thereby tends to emphasise the stark differences between the two and to overlook the possibility that these frameworks may be complementary rather than mutually exclusive' (Einsiedel 2000). Furthermore, the idea that survey based analyses are not capable of or suitable for demonstrating a contingent or mediated relationship between knowledge and attitude does not bear close scrutiny. Evans and Durant (1995), for example, show that while the simple deficit model holds for attitudes to science in general, better informed respondents tend to be among the most sceptical when it comes to 'morally contentious' and 'non-useful' sciences. Similarly, Bauer, Evans and Durant (1994), in another multi-variate statistical analysis, show that the strength of the knowledge-attitude relationship varies across Europe according to national levels of economic advancement. However, while these studies demonstrate, through quantitative analysis, the contingent nature of the knowledge attitude nexus, they do not focus specifically on the mediational or contextualising form of knowledge as set out, however imprecisely, by those propounding this theoretical model. 
The present research is motivated by a concern to address this gap in the empirical literature; we believe that potentially valuable theoretical insights and developments in the field of public understanding of science are being stymied by the paradigmatic formalisms and methodological orthodoxies of divergent research traditions. Rather than seeing the contextualist perspective as a potentially decisive critique of the deficit model, we hope in this paper to show how these two theoretical perspectives might be integrated in a more complex and complete account of how what people know about science and the context in which it is practised affects their general favourability toward science and the scientific community. In using a quantitative, survey based approach as the vehicle in this regard, we do not aim to pick it out as the methodological 'royal road', but, rather, aim to illustrate how both the deficit and contextualist models might be investigated from this particular perspective.

\section{MEASURING CONTEXTUAL KNOWLEDGE}

The key problem, of course, in integrating the contextualist perspective within a survey based quantitative analysis is obtaining satisfactory operationalisations of the relevant knowledge domains. Finding adequate indicators of hypothetical and unobservable concepts is difficult at the best of times (Hox, 1997). The process is at its most treacherous when, as in the current instance, the concepts in question are 'fuzzy', multi-dimensional and, to a large degree, contested. However, the potentiality of biased or unreliable measurement should not, we would argue, lead us to abandon the idea that there might be something of interest to be measured. Rather, the question that needs to be addressed is: how can we obtain the best measurements?

The notion of contextualising knowledge is not, to be sure, a domain of specified and particular content in and of itself. Rather, it expresses the idea of an interacting causal mechanism between two or more independent variables and an unspecified dependent variable. Earlier we briefly reviewed some of the definitions and examples that proponents of 
the contextualist perspective have suggested might constitute knowledge domains that act in such a way in combination with factual scientific knowledge and attitudes toward science. We would summarise these as falling into either of two main categories: 'institutional knowledge of science' denoting an understanding of the ways in which science is embedded within wider political, economic and regulatory settings and 'local knowledge' which we take to mean knowledge of the ways in which specific applications of science or technology connect with everyday practices in particular contexts. As we are here focusing on the national picture, using data that is representative of the GB population rather than any specific localities, we focus our attention on the former of these. There is, however, no reason why the analytical approach we adopt here could not equally well be applied to small area data if an appropriate measure of the relevant 'local knowledge' in question were available.

So how does one go about measuring the average citizen's knowledge of the political and institutional relationships in which science and the development of science policy and regulation is embedded? Well, here we propose that the answer truly is in the question. For what we are surely dealing with here is a kind of 'political sophistication' - a concept which has undergone a great deal of theoretical and empirical scrutiny in the field of political science over the last thirty or so years (Luskin 1987). This programme of research has repeatedly demonstrated that, firstly, individual citizens vary enormously in the amount they know about politics and that, secondly, one's level of political knowledge has a significant impact on one's political preferences, likelihood of voting and a whole host of other important behaviours, attitudes and beliefs (Converse 2000, Delli-Carpini and Keeter 1996). What it has also shown is that, as with most areas of knowledge or intelligence, in politics people tend to be 'generalists', such that their level of knowledge in any one particular domain will be highly predictive of their level of knowledge in another. So people who know the names and faces of political 'actors' also tend to know about the institutions of government and where parties and candidates stand on the major issues of the day. For example, Delli Carpini and Keeter have shown that, in two recent US surveys, the average correlation 
between scales measuring knowledge about political 'players' and the policy stances of political parties is approximately .80 . They also find that, in a range of US surveys, the lowest correlation between sub-domains of political knowledge (drawn from a pool of ten different domains) is as high as .52 , while the greatest is .97 .

Based on results like these, we would argue that if we can distinguish between individuals in terms of their level of political knowledge, such a measure is also likely to be discriminative of the extent to which people are aware of the political and institutional relationships within which the practice and regulation of science and technology is located. Let us not forget, after all, that the ways in which science is practised, regulated and deployed in society is still essentially a 'political' matter.

So while political knowledge batteries - as routinely implemented in surveys of political attitudes and behaviour - are clearly not direct measures of the 'institutional knowledge of science' construct as set out above, we believe that they will likely act as reasonably good proxies: people who are knowledgeable about political parties and the issue positions they endorse, are also more likely to be familiar with existing forms of scientific regulation, government committee structures, the nature of links between science, industry and government and so forth.

An additional reason for preferring this particular operationalisation in the analysis is the difficulty of obtaining purely factual 'answers' to any questions that might otherwise be used as indicators. Bauer, Petkova and Boyadjieva (2000) have developed a set of items designed to measure what they also term 'institutional knowledge of science'. They found that 'institutional knowledge' comprises two sub-domains of belief about a) the autonomy of scientists and b) the ways in which institutions function. However, they themselves acknowledge the potential pitfalls of trying to directly assess this type of knowledge by pointing to what they the see as the inherently contested nature of 'facts' about institutions. As a result, the problem with Bauer et al.'s scale is that too many of the items, in the absence 
of any objective means of determining the 'correct' response, stray from the knowledge into the attitudinal domain ${ }^{4}$. As we are here primarily interested in how different domains of knowledge impact on attitude toward science, we feel that it is of paramount importance to employ measures of knowledge that have, without descending into solipsism, easily verifiable right or wrong answers. It is therefore, we believe, preferable to use a less direct but verifiably a knowledge based measure of our key theoretical construct than a more direct but also a more ambiguous and contestable one.

\section{ANALYSIS}

From the discussion above it is possible to deduce a number of empirical hypotheses concerning the relationship between the favourability of people's attitudes toward science and their level of political and scientific sophistication. These are tested on data from a survey of a representative sample of the British population. Firstly, then, the deficit model holds that a generally negative attitude toward science is underpinned by, inter alia, a lack of 'textbook' scientific knowledge. Our first hypothesis therefore becomes:

H1 - The main effect of scientific knowledge on general attitude toward science controlling for a range of important demographic characteristics - will be significant and positive.

The contextualist account, on the other hand, contends that understanding of the relationships between political and financial institutions and the scientific community is at least as important as scientific knowledge and will, in the aggregate, serve to diminish or even counteract any simple positive linear relationship between textbook scientific knowledge and attitude toward science. Our second hypothesis is therefore: 
H2 - The main effect of political knowledge on general attitude toward science controlling for a range of important demographic characteristics and scientific knowledge will be significant and negative.

If the contextualist account is correct, we would also expect that political knowledge will act to moderate the effect of scientific knowledge in the formation of attitudes. In other words, for people with a lot of knowledge about politics and institutional decision-making, scientific knowledge will not be related to attitudes in the same way as it is for those without much political awareness. Accordingly, our third hypothesis is:

H3 - The effect of scientific knowledge on attitude toward science will vary as a function of level of political knowledge.

Finally, the contextualist account sees contextual knowledge as a kind of 'protective filter', endowing us with an important scepticism concerning the aims, objectivity and independence of the scientific community. Thus, while we might expect to see a strong correlation between textbook scientific knowledge and acceptance of science for those less knowledgeable in this domain, any such relationship should also steadily diminish as the stock of political knowledge increases. Our fourth hypothesis (conditional on non-rejection of H3) therefore becomes:

H3b - the positive effect of scientific knowledge on attitude toward science will be greatest at low levels of political knowledge and will be much diminished at higher levels of political knowledge. 
These hypotheses are tested using Ordinary Least Squares (OLS) regression on a scale measuring favourability of attitude toward science and applications of scientific knowledge. Data come from the 1996 British Social Attitudes Survey (Jowell, Curtice, Park, Brook, Thomson and Bryson 1997) that contains the necessary measures of all key variables. ${ }^{5}$ The dependent variable is an additive scale comprising four five-point Likert items (Cronbach's Alpha $=0.53)^{6}$ that measure a general attitude toward science and the benefits of technological innovation. These questions have been included in a number of previous surveys and have been used to create a measure of general attitude toward science in a number of studies (Bauer, Durant and Evans 1994, Evans and Durant 1995, Miller, Pardo and Niwa 1997, Pardo and Calvo 2002). Exact wordings for these items are provided in the appendix. Raw scores on the summed scale have a possible range of zero to sixteen as the individual items were all coded zero (least favourable) to four (most favourable). To facilitate interpretation and comparability with the other key variables in the analysis, the raw scores were converted into percentiles, representing the percentage of respondents at each value of the raw scale. Respondents at a particular level of the scale were assigned the mid-point of the set of percentiles covered by that particular value. Thus, for example, 0.2 per cent of respondents had the lowest score on the raw summed scale. These respondents were assigned a percentile score of 0.001 , representing the mid-point of this set of percentiles on a zero to one scale. Higher scores on this scale therefore indicate a more favourable attitude toward science. A histogram of the raw scale score is presented in the appendix.

As a measure of scientific knowledge we use a ten-item subset of the scale originally developed by Durant, Evans and Thomas (1989) that subsequently became known as the 'Oxford' scale of scientific knowledge. The subscale used here (range $=0-10$ ) taps a range of areas of scientific knowledge (Cronbach's Alpha $=0.68)$. These include; understanding of probability theory; understanding of the nature of scientific enquiry; understanding of experimental design and control groups; and a number of areas of 'textbook' scientific knowledge. Raw scale scores were also converted to a percentile measure as outlined 
above. Exact wordings for these items and details of codings of correct/incorrect responses are provided in the appendix.

For our measure of political knowledge, we use a six-item scale tapping respondent knowledge of the policy stances of the main political parties in Great Britain (Cronbach's Alpha $=0.66)$. Raw scores ranged from zero to six and were also converted to a percentile measure to ease interpretation and comparability. Exact wordings and coding schemes are provided in the appendix.

\section{RESULTS}

Table 1 shows the results of three OLS regression models predicting general attitude toward science. Predictors in the models are political affiliation; age; sex; religiosity; social class; scientific qualifications; general educational attainment; marital status; and employment status. Political knowledge, scientific knowledge and their interaction are incorporated in the models in iterative steps. The results of Model 1 clearly support $\mathrm{H} 1$, with a positive and highly significant coefficient of $0.286(p<0.001)$ for scientific knowledge, even in the presence of other important determinants of general attitude toward science. Note also that the majority of other independent variables in the model are significant at the $p<0.05$ level or lower and in the expected direction - being male, younger, non-religious, right wing, having scientific qualifications and being in a non-manual social-class are all positively associated with a more favourable attitude toward science.

Model 2 incorporates all the independent variables in Model 1 but this time adds political knowledge as a predictor in the model. The significant and positive main effect of political knowledge does not support $\mathrm{H} 2$ but in fact shows that the opposite of $\mathrm{H} 2$ pertains greater levels of political knowledge also lead to a more favourable attitude toward science. This finding would appear to be at odds with the contextualist perspective. For the contextualist critique of the deficit model argues that it provides an overly simple, holistic 
account of the knowledge-attitude relationship and that considering other domains of knowledge such as 'institutional knowledge of science' as determinants of attitude would show a reversal of the positive association commonly found between 'textbook' scientific knowledge and attitude toward science.

\section{TABLE 1 HERE}

Our interpretation here depends crucially, of course, on acceptance of the political knowledge measure acting as a reasonable proxy for the 'institutional knowledge of science' domain described by contextualist accounts - a point which we consider at greater length below. Note also that the $R^{2}$ increases significantly and that the coefficients for the other independent variables are not much affected as a result of the inclusion of political knowledge in the model. The biggest change is in the negative coefficient for sex (female) indicating that at least some of the negative attitude toward science amongst women may be due to the difference in levels of political knowledge between the sexes.

Model 3 further elaborates on Models 1 and 2 by including the interaction of political and scientific knowledge as an additional predictor of attitude toward science. What the significant interaction parameter in Model 3 shows then, is that there is indeed a contextualising or moderating effect of political knowledge on the relationship between textbook scientific knowledge and attitude toward science, supporting hypothesis $\mathrm{H} 3$. Someone with the lowest level of political knowledge (zero) and the lowest level of scientific knowledge (zero) would have a predicted score of .49 (the intercept) on the attitude toward

science variable (that is to say they would be on the $49^{\text {th }}$ percentile of the attitude variable). If someone has the lowest score on the political knowledge measure, a one unit increase in scientific knowledge would lead to a .18 increase in attitude toward science. If someone has the lowest score on the scientific knowledge score, however, a one unit increase in political knowledge would lead to only a .008 increase in attitude toward science. The positive 
coefficient for the interaction of political and scientific knowledge indicates that, for every one unit increase in political knowledge, the slope of attitude toward science on scientific knowledge increases by 0.16 or, equivalently, for every one unit increase in scientific knowledge, the slope of attitude toward science on political knowledge increases by 0.16 . Thus, at all levels of scientific knowledge, the effect of growth in political knowledge is to further enhance the already favourable attitude. This is counter to what the contextualist model would predict as specified in hypothesis H3b. The same 'amplification' effect applies equally to scientific knowledge, which maintains a positive slope on attitude toward science at all levels of political knowledge - with the largest coefficients appearing at higher levels of political knowledge.

The nature of this interacting effect between political and scientific knowledge on attitude toward science can be represented in three dimensional space by taking the predicted score on the attitude dependent variable from Model 3 at each combination of levels of the other two variables as shown in Figure 1.7 Figure 1 clearly illustrates the curvilinear relationship between each knowledge domain and attitude toward science. Note how the regression plane always moves in an upward direction on the $Z$ axis with increases in scientific or political knowledge. The group most favourable toward science are those at the top percentile of both knowledge dimensions, while the least favourable are those with the lowest score on political knowledge and the minimum on the scientific knowledge scales. For those at the highest level of political knowledge, moving from the bottom to the top of the scientific knowledge scale alone results in a increase in favourability of attitude toward science of almost thirty percentiles. This compares with a more modest jump of around seventeen percentiles for the same increase in scientific knowledge amongst those at the lowest level of political knowledge

\section{FIGURE 1 HERE}


This then appears to be the reverse of what the contextualist account would lead us to expect - rather than political knowledge acting to attenuate the positive effect of 'textbook' scientific knowledge on attitude toward science, it actually appears to amplify the existing positive association. Furthermore, of the two domains, scientific knowledge appears to be far the stronger determinant of attitude toward science. The largest increase in favourability of attitude caused by increasing political knowledge is 14 per cent while the equivalent figure for scientific knowledge is more than double that amount. This can be seen from the fact that the angle of elevation of the regression plane in Figure 1 is more oblique from left to right than it is from front to back.

\section{DISCUSSION}

We have tried in this paper to show how the contextualist and deficit perspectives in public understanding of science might be integrated within a survey-based quantitative analysis. In doing so we hope to open up a more open and fruitful dialogue between researchers in the field who come, perhaps, from different methodological and epistemological research traditions. Too often methodological formalism and theoretical orthodoxy seems to prevent the useful cross-fertilisation of ideas and stifles the progression and refinement of theory. To be sure, we recognise that there are a number of problems and limitations in our approach and do not claim that the conclusions we draw concerning the complex relationship between different domains of knowledge and attitude toward science are definitive. Nonetheless, many of the caveats we ourselves would place on these results derive from circumstances beyond our control; we have had, for example, to rely on analysis of secondary data and, to that extent, have not been able to develop our own operationalisations of key constructs in our theoretical models. For this reason we hope that readers will see this analysis as a position piece to be elaborated and improved upon in the future. 
We anticipate two primary lines of objection to our analysis and the conclusions we have drawn from it. To those who contend that these sorts of questions are simply not amenable to a quantitative, survey-based approach, we have little to say in reply ${ }^{8}$. It is not the aim of this paper to counter a generalised scepticism of the survey method (indeed any sceptics reading this paper are more likely to have had their prejudices confirmed) but to show how these two important theoretical perspectives might be integrated within a single methodological study. More forceful criticism will concern the operationalisations of our key theoretical constructs: 'general attitude toward science', 'textbook knowledge of science' and 'institutional knowledge of science', to which we turn below.

We are aware that the use of such a generalised measure of attitude toward science raises issues of the exact meaning of such an abstract construct and whether our results can, in any way, be expected to apply to more concrete and localised contexts. One does, of course, need to be extremely careful when interpreting general attitudes and their relationship to more specific opinions and behaviours (Ajzen and Fishbein 1980). Nevertheless, we believe that an overall evaluation of science as measured here is diagnostic of a wider set of attitudes, values and beliefs reflecting a person's disposition towards the social integration of technological innovation and 'scientific progress' and concur with Evans and Durant who argue that such a construct has real social force and meaning in that it represents evaluations of science as "a set of principles, a way of understanding the world, or as a profession' (Evans and Durant 1995).

As regards our measures of scientific and political knowledge, we accept that knowing the answers to these items in isolation cannot be conceived of as very interesting or useful for understanding someone's attitude toward science in society. How can knowledge or ignorance of a set of true/false questions in a survey tell us anything of any value about someone's real understanding of science or politics? This line of criticism, however, fundamentally misses the point of measurement using diagnostic indicators. For, as we have 
already pointed out, there is good evidence to suggest that people do not tend to learn things in isolation (Evans and Durant 1995, Gaziano and Gaziano 1996, Miller 1983, Miller 1998, Popkin and Dimock 1999, Tichenor, Donohue and Olien 1970). It is likely, for example, that a person who obtains a high score on this particular science quiz also has a range of other relevant scientific knowledge and understanding that, taken together, influence the formation of their attitude toward science. Confusing the contents of the measurement instrument with the attitude or trait underlying responses to it is a common mistake among critics of quantitative approaches to PUS. But, as Philip Converse has remarked, 'it does not take much imagination to realise that knowledge of minor facts....are diagnostic of more profound differences in the amount of contextual information citizens bring to their judgments' (Converse 2000). The items selected for this analysis should accordingly be seen as diagnostic indicators rather than fully constitutive of the actual scientific and political knowledge relevant to attitude formation.

One need not disagree with our position here, however, to argue that our measure of political knowledge is not tapping the kind of awareness of "patronage, organisation and control' that is stressed within the contextualist treatment of 'institutional knowledge of science'. While acknowledging the need for further work and replication for delineating the measurement properties of this construct, we believe that we have summoned ample evidence pointing to the validity and reliability of such measures in general. And, furthermore, there is no particular reason why awareness of science and technology policy and regulation should not be among the other political issues, knowledge of which is known to correlate with these sorts of items. Finally, if it could be shown that the type of policy related political knowledge that we have used here has, in fact, little to do with the type of 'institutionalrelational' knowledge that we are attempting to tap, it begs the question of why this type of political knowledge is related to the formation of attitudes towards science in the way we have shown it to be. 


\section{CONCLUSION}

The results as they stand lend some support to the contextualist perspective, although not perhaps in the way we might have expected. The effect of scientific knowledge on attitude toward science is not a straightforward linear main effect, but does indeed appear to be 'contextualised' by at least one other domain of knowledge. This domain, we have argued, is that which Wynne (1992) has described as representing an individual's understanding of the 'patronage, organisation and control' operating in and around science and the scientific community. Contrary to what the contextualist critique of the deficit model would lead us to expect, however, the effect of this knowledge domain seems to operate in ways similar to 'textbook' scientific knowledge, augmenting the already positive influence of the latter domain on favourability of attitude toward science. This latter result leads us to suggest a possible mechanism underlying these findings.

Popkin and Dimock (1999) observe that respondents with low levels of political knowledge tend to see political scandal as much more serious than those with higher levels of political knowledge and understanding. They use Attribution Theory and, in particular, the notion of the 'Fundamental Attribution Error' (Jones and Nisbett 1971) to explain why this might be so. Attribution research has shown that people tend to interpret the behaviour of others as indicative of character, while tending to attribute their own behaviour to circumstances (Watson 1982). In other words, if a Member of Parliament writes a bounced cheque it is because she is untrustworthy; if I write a bounced cheque it is because I was so busy that I forgot to first make sure I had sufficient funds. Furthermore, because we also tend to overestimate the reasonableness of our own actions, we also overestimate the probability that others would do the same as us. When this is not the case, we tend to attribute the difference to 'bad character' (Ross and Anderson 1982). Because a key moderating factor in the tendency to make internal attributions is the amount of contextual information available to observers, Popkin and Dimock argue that those with more political knowledge better 
understand the constraints and contexts in which political behaviour takes place. The more situations and contexts in which one has observed these actions, the less likely it is that behaviour will be attributed to character.

This, of course, is entering the realms of post-hoc speculation but has, we feel, important implications for the interpretation of the findings that we have presented in this paper, in addition to highlighting a promising avenue for future research. The effect of scientific knowledge on the attitudes of respondents whose knowledge of politics is high is greater than it is for those with low political knowledge. With a greater degree of political understanding and awareness, it may be that people are less likely to attribute the less fortunate outcomes of scientific development to the bad character of scientists or politicians but to a more complex set of institutional, political and other 'situational' factors. Hence, whatever leads knowledge of science to increase one's favourability towards it, is even more effective when people are familiar with the complex range of circumstances surrounding scientific and technological development within the wider political landscape.

In making these observations we are convinced that, firstly, both deficit and contextualist perspectives help to explain how, why and under what conditions knowledge of many kinds is important in determining public attitudes towards science and, secondly, that survey-based approaches are by no means unsuitable for research into public understanding of science from a 'contextualist' theoretical perspective.

\section{Notes}

1 An earlier version of this article was presented at the World Association of Public Opinion Research (WAPOR) Annual Conference, Date, Rome, Italy.

2 We use this term to denote this perspective because, in this view, knowledge of science is seen not as an abstract canon of 'facts' but as sets of understandings within varying practical and social contexts. The effect of one form of understanding on attitude will, in this view, be contextualised by other areas of knowledge. 
3 We are here interpreting Einsiedel's use of 'interactive science model' as being equivalent or nearly equivalent to what we refer to as the contextualist perspective.

4 The survey uses a multi-stage sampling design and is representative of the UK adult population. It was carried out by Social and Community Planning Research and achieved an overall response rate of 65 per cent.

5 While this coefficient is well below the traditional cut-off criterion for scale reliability of 0.7 , more sophisticated scale assessment using Confirmatory Factor Analysis (CFA) suggests a one factor model fits the data extremely well $(X 2=0.2 ; d f=1 ; p=0.647)$, with all 4 indicators contributing significantly $(p<0.001)$ to the common factor variance.

6 The predicted scores assume values of zero on all other independent variables in the model.

7 However, we point such readers in the direction of King, Keohane and Verba (1994) and Goldthorpe (2000) for excellent expositions in this regard.

8 They include as 'knowledge' items, statements such as 'The reward of scientific research is recognition rather than money' and 'For the industrialized countries investment in science is a top priority' which we consider express unverifiable beliefs that are more indicative of attitudes. 


\section{Bibliography}

I. Ajzen and M. Fishbein, Understanding attitudes and predicting social behavior (Englewood Cliffs, NJ: Prentice Hall, 1980).

M. Bauer, J. Durant and G. Evans, "European public perceptions of science," International Journal of Public Opinion Research, volume 6, 2 1994, pp. 163-186.

M. Bauer, K. Petkova and P. Boyadjieva, "Public knowledge of and attitudes to science: alternative measures that may end the "science war"," Science, Technology and Human Values, volume 25, 12000 , pp. 30-51.

W. Bodmer, "The Public

Understanding of Science," (London: Royal Society, 1985).

P. E. Converse, "The nature of belief systems in mass publics," in Ideology and discontent,

D. E. Apter, ed. (New York: Free Press, 1964), pp. 206-261.

P. E. Converse, "Assessing the capacity of mass electorates," Annual Review of Political Science, 32000 , pp. 331-53.

M. X. Delli-Carpini and S. Keeter, What Americans Know about Politics and Why It Matters (New Haven: Yale University Press, 1996).

M. Douglas and A. Wildavsky, Risk and culture: an essay on the selection of technical and environmental dangers (Berkeley: University of California Press, 1982).

J. Durant, G. Evans and P. Thomas, "The public understanding of science," Nature, volume 340, 6228 1989, pp. 11-14.

E. Einsiedel, "Understanding "publics" in the public understanding of science," in Between understanding and trust: the public, science and technology, M. Dierkes and C. von Grote, ed. (Amsterdam: Harwood, 2000).

G. Evans and J. Durant, "The relationship between knowledge and attitudes in the public understanding of science in Britain," Public Understanding of Science, volume 4, 1 1995, pp. 57-74.

G. Gaskell, N. C. Allum, W. Wagner, T. Hviid Nielsen, E. Jelsoe, M. Kohring and M. Bauer, "In the public eye: representations of biotechnology in Europe," in Biotechnology 1996-2000: the years of controversy, G. Gaskell and M. Bauer, ed. (London: Science Museum Publications, 2001).

C. Gaziano and E. Gaziano, "The knowledge gap: theories and methods in knowledge gap research since 1970," in An integrated approach to communication theory and research, M. B. Salwen and D. W. Stack, ed. (New York: Erlbaum Mahwah, 1996), pp. 127-143.

J. H. Goldthorpe, On Sociology (Oxford: Oxford University Press, 2000). 
J. Gregory and S. Miller, Science in public: communication, culture and credibility (New York: Plenum Press, 1998).

M. C. Grimston, "Public opinion surveys in the UK," Nuclear Europe Worldscan, volume 14, 7-8 1994, pp. 98.

A. G. Gross, "The roles of rhetoric in the public understanding of science," Public Understanding of Science, volume 3 1994, pp. 3-23.

I. Hargreaves, "Who's misunderstanding whom? - an inquiry into the relationship between science and the media," Economic and Social Research Council, 2000).

B. C. Hayes and V. N. Tariq, "Gender differences in scientific knowledge and attitudes toward science: a comparative study of four Anglo-American nations," volume 9, 4 2000, pp. 433-447.

B. C. Hayes and V. N. Tariq, "Gender differences in scientific knowledge and attitudes toward science: a reply to a reply," Public Understanding of Science, volume 10, 4 2001, pp. 431-433.

House of Lords Select Committee on Science and Technology, "Science and Society; Third Report of the Session 1999-2000," (London: HM Stationery Office, 2000).

INRA, "Biotechnology and genetic engineering. What Europeans think about in 1993," Survey conducted in the context of Eurobarometer 39.1, 1993).

A. Irwin and B. Wynne, Misunderstanding science? The public reconstruction of sciene and technology (Cambridge: Cambridge University Press, 1996).

S. Jasanoff, "The "science wars" and American politics," in Between understanding and trust: the public, science and technology, M. Dierkes and C. von Grote, ed. (Amsterdam: Harwood, 2000).

E. E. Jones and R. E. Nisbett, "The actor and the observer: divergent perceptions of the causes of behavior," in Attribution: perceiving the causes of behavior, E. E. Jones, D. E. Kanouse, H. Kelley, R. E. Nisbett, S. Valins and B. Weiner, ed. (Morristown, NJ: General Learning Press, 1971).

R. Jowell, J. Curtice, A. Park, L. Brook, K. Thomson and C. Bryson, eds. British Social Attitudes: the 14th Report: the end of Conservative values? (Aldershot: Ashgate Publishing, 1997).

A. Kerr, S. Cunningham-Burley and A. Amos, "The new genetics and health: mobilizing lay expertise," volume 7, 1 1998, pp. 41-60.

G. King, R. O. Keohane and S. Verba, Designing social enquiry: scientific inference in qualitative research (Princetown, New Jersey: Princetown University Press, 1994).

D. Layton, E. Jenkins, S. McGill and A. Davey, Inarticulate science? perspectives on the public understanding of science and some implications for science education (East Yorkshire: Studies in Education Ltd, 1993). 
R. C. Luskin, "Measuring political sophistication," American Journal of Political Science, volume 31 1987, pp. 856-899.

M. K. McBeth and A. S. Oakes, "Citizens's perceptions of risks associated with moving radiological waste," Risk Analysis, volume 16 1996, pp. 421-427.

M. Michael, "Lay discourses of science: science-in-general, science-in-particular, and self'," Science, Technology and Human Values, volume 17 1992, pp. 313-333.

M. Michael, "Ignoring science: discourses of ignorance in the public understanding of science," in Misunderstanding science? the public reconstruction of science and technology, A. Irwin and B. Wynne, ed. (Cambridge: Cambridge University Press, 1996).

J. D. Miller, "Scientific literacy: a conceptual and empirical review," Daedalus, volume 11 1983, pp. 29-48.

J. D. Miller, "The measurement of scientific literacy," Public Understanding of Science, volume 7 1998, pp. 203-223.

J. D. Miller, R. Pardo and F. Niwa, Public perceptions of science and technology: a comparative study of the European Union, the United States, Japan and Canada (Bilbao: Fundacion BBV, 1997).

S. Miller, "Public understanding of science at the crossroads," Public Understanding of Science, volume 10 2001, pp. 115-120.

D. Nelkin and M. S. Lindee, The DNA mystique. The gene as a cultural icon (New York: W. H. Freeman and Company, 1995).

Office of Science and Technology and the Wellcome Trust, "Science and the public: a review of science communication and public attitudes toward science in Britain," Public Understanding of Science, volume 10 2001, pp. 315-330.

R. Pardo and F. Calvo, "Attitudes toward science among the European public: a methodological analysis," Public Understanding of Science, volume 11 2002, pp. 155-195.

H. P. Peters, "From information to attitudes? Thoughts on the relationship between knowledge about science and and technology and attitudes toward technology," in Between understanding and trust: the public, science and technology, M. Dierkes and C. von Grote, ed. (Amsterdam: Harwood, 2000).

S. L. Popkin and M. A. Dimock, "Political knowledge and citizen competence," in Citizen competence and democratic institutions, S. L. Elkin and K. E. Soltan, ed. (University Park, Pennsylvania: The Pennsylvania State University Press, 1999).

S. H. Priest, A grain of truth: the media, the public, and biotechnology (Oxford: Rowman and Littlefield, 2001).

S. H. Priest, "Misplaced faith: communication variables as predictors of encouragement for biotechnology development," Science Communication, volume 23, 2 2001, pp. 97-110.

L. Ross and C. Anderson, "Shortcomings in the attribution process: on the origins and maintenance of erroneous assessments," in Judgment under uncertainty: heuristics and 
biases, D. Kahneman, P. Slovic and A. Tversky, ed. (Cambridge: Cambridge University Press, 1982), pp. 143-157.

M. Siegrist, G. Cvetkovich and C. Roth, "Salient value similarity, social trust, and risk/benefit perception," Risk Analysis, volume 20, 3 2000, pp. 353-362.

P. Slovic and E. Peters, "The Importance of Worldviews in Risk Perception," Journal of Risk Decision and Policy, volume 3, 2 1998, pp. 165-170.

P. M. Sniderman, J. M. Glaser and R. Griffin, "Information and electoral choice," in Information and democratic processes, J. Ferejohn and J. Kuklinski, ed. (Urbana, IL: University of Illinois Press, 1990).

P. Sturgis and N. C. Allum, "The impact of knowledge on attitudes toward biotechnology: using regression models to simulate a better-informed public," (Nottingham: British Psychological Society (Social Psychology Section) 2000).

P. J. Sturgis and N. C. Allum, "Gender differences in scientific knowledge and attitudes toward science: reply to Hayes and Tariq," Public Understanding of Science, volume 10, 4 2001, pp. 427-430.

P. J. Tichenor, G. A. Donohue and C. N. Olien, "Mass media and differential growth in knowledge," Public Opinion Quarterly, volume 34 1970, pp. 158-170.

A. Touraine, "The crisis of progress," in Resistance to new technology - nuclear power, information technology, biotechnology, M. W. Bauer, ed. (Cambridge: Cambridge University Press, 1985), pp. 45-56.

D. Watson, "The actor and the observer: how are their perceptions of causality divergent?," Psychological Bulletin, volume 92 1982, pp. 682-700.

S. B. Withey, "Public opinion about science and scientists," Public Opinion Quarterly, volume 23 1959, pp. 382-388.

B. Wynne, "Knowledges in context," Science, Technology and Human Values, volume 16, 1 1991, pp. 111-121.

B. Wynne, "Public understanding of science research: new horizons or hall of mirrors?," Public Understanding of Science, volume 1, 1 1992, pp. 37.

B. Wynne, "Public understanding of science," in Handbook of science and technology studies, S. Jasanoff, G. Markle, J. Petersen and T. Pinch, ed. (Thousand Oaks, Ca.: Saga Publications, 1995), pp. 361.

S. Yearley, "What does science mean in the "public understanding of science"?," in Between understanding and trust: the public, science and technology, M. Dierkes and C. von Grote, ed. (Amsterdam: Harwood, 2000).

J. Ziman, "Public understanding of science," Science, Technology and Human Values, volume 16 1991, pp. 99-105. 
TABLES AND FIGURES

TABLE 1 OLS Regression Models Predicting General Attitude Toward Science

\begin{tabular}{|c|c|c|c|}
\hline Variables in Model & Model 1 & Model 2 & Model 3 \\
\hline Constant & $\begin{array}{l}.468^{* * *} \\
(.028)\end{array}$ & $\begin{array}{l}.453^{* * *} \\
(.028)\end{array}$ & $\begin{array}{l}.488^{\star \star \star} \\
(.032)\end{array}$ \\
\hline Scientific Knowledge & $\begin{array}{l}.286^{\star * *} \\
(.023)\end{array}$ & $\begin{array}{l}.254^{* * *} \\
(.024)\end{array}$ & $\begin{array}{l}.176^{\star \star *} \\
(.043)\end{array}$ \\
\hline Favours Labour Party & $\begin{array}{l}-.012^{*} \\
(.005)\end{array}$ & $\begin{array}{l}-.010+ \\
(.005)\end{array}$ & $\begin{array}{l}-.009+ \\
(.005)\end{array}$ \\
\hline Age & $\begin{array}{l}-.001^{* * *} \\
(.000)\end{array}$ & $\begin{array}{l}-.002^{* * *} \\
(.000)\end{array}$ & $\begin{array}{l}-.002^{* * *} \\
(.000)\end{array}$ \\
\hline Female & $\begin{array}{l}-.066^{* * *} \\
(.011)\end{array}$ & $\begin{array}{l}-.053^{* * *} \\
(.012)\end{array}$ & $\begin{array}{l}-.052^{* * *} \\
(.012)\end{array}$ \\
\hline Attends Church & $\begin{array}{l}-.058^{* * \star} \\
(.014)\end{array}$ & $\begin{array}{l}-.062^{* * *} \\
(.014)\end{array}$ & $\begin{array}{l}-.063^{* \star *} \\
(.014)\end{array}$ \\
\hline Non-manual class & $\begin{array}{l}.053^{* * *} \\
(.012)\end{array}$ & $\begin{array}{l}.048^{* * *} \\
(.012)\end{array}$ & $\begin{array}{l}.047^{\star \star *} \\
(.012)\end{array}$ \\
\hline Science qualification & $\begin{array}{l}.056^{\star * *} \\
(.014)\end{array}$ & $\begin{array}{l}.050^{* * *} \\
(.014)\end{array}$ & $\begin{array}{l}.048^{* * *} \\
(.014)\end{array}$ \\
\hline Higher Degree & $\begin{array}{l}.013 \\
(.014)\end{array}$ & $\begin{array}{l}.007 \\
(.014)\end{array}$ & $\begin{array}{l}.005 \\
(.014)\end{array}$ \\
\hline Marital Status & $\begin{array}{l}-.020+ \\
(.012)\end{array}$ & $\begin{array}{l}-.022+ \\
(.012)\end{array}$ & $\begin{array}{l}-.021+ \\
(.012)\end{array}$ \\
\hline Employment status & $\begin{array}{l}.007 \\
(.012)\end{array}$ & $\begin{array}{l}.005 \\
(.012)\end{array}$ & $\begin{array}{l}.005 \\
(.012)\end{array}$ \\
\hline Political Knowledge & & $\begin{array}{l}.087^{* * *} \\
(.024)\end{array}$ & $\begin{array}{l}.008 \\
(.043)\end{array}$ \\
\hline Political * Scientific Knowledge & & & $\begin{array}{l}.158^{* * *} \\
(.072)\end{array}$ \\
\hline $\mathrm{R}^{2}$ & .211 & .215 & .217 \\
\hline Standard error of the regression & .256 & .255 & .255 \\
\hline Significance of change in $R^{2}$ & - & .005 & .002 \\
\hline F Statistic & $61.906^{* * *}$ & $57.792^{* * *}$ & $53.473^{* * *}$ \\
\hline
\end{tabular}

$+p<0.10 ;{ }^{*} p<0.05 ;{ }^{* *} p<0.01 ;{ }^{* * *} p<0.001$.

Notes $=$ Standard errors in parentheses. Number of cases $=2328$.

Source: British Social Attitudes Survey 1996 
FIGURE 1 Joint Effect of Scientific / Political Knowledge on Attitude toward Science

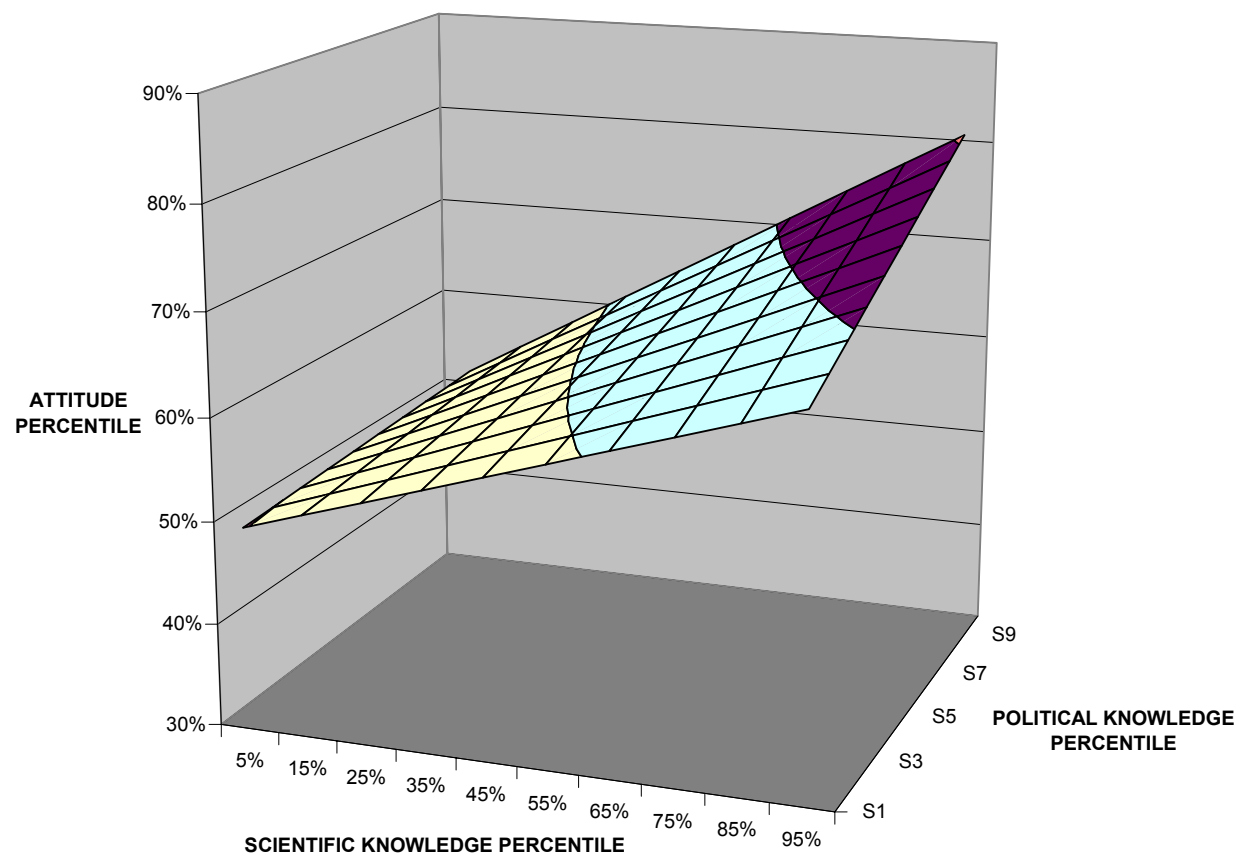




\section{APPENDIX}

\section{Wordings and Coding of Items in Attitude toward Science Scale}

1. science and technology make life healthier, easier and more comfortable.

2. we depend too much on science and not enough on faith.

3. science makes life change too fast.

4. it is not important for me to know about science in my daily life.

All items are five point Likert response scales ranging from strongly disagree (0) to strongly agree (4).

\section{Wordings and Coding of Items in Political Knowledge Scale}

The political knowledge measure is a summed scale of the following six items:

These next questions are about things that different parties are in favour of. If you feel you don't know, just tell me and we'll go to the next question. Firstly which party would you say is...

1. Most in favour of changing the voting system to a form of proportional representation?

For the knowledge scale this was recoded: Lib Dems $=$ correct $(1)$, all other answers $=$ incorrect (0).

2. Most in favour of reducing government spending in order to cut taxes?

For the knowledge scale this was recoded: Tories $=$ correct $(1)$, all other answers $=$ incorrect (0).

3. Most in favour of schools being under local authority control?

For the knowledge scale this was recoded: Labour = correct $(1)$, all other answers $=$ incorrect $(0)$. 
4. Most in favour of independence for Scotland?

For the knowledge scale this was recoded: SNP = correct $(1)$, all other answers $=$ incorrect $(0)$.

5. Most in favour of letting private industry run the railways?

For the knowledge scale this was recoded: Tories = correct $(1)$, all other answers $=$ incorrect $(0)$.

6. Most in favour of setting a minimum wage level, below which no-one can be paid? For the knowledge scale this was recoded: Labour = correct $(1)$, all other answers $=$ incorrect (0).

\section{Wordings and Coding of Items in Scientific Knowledge Scale}

The scientific knowledge measure is a summed scale of the following ten items:

1. Some news stories talk about the results of a 'scientific study'. When you read or hear this term, can you tell me in your own words what you think it means to study something scientifically.

VERBATIM RESPONSES CODED TO:

1. Theory construction and testing

2. To undertake tests/experiments

3. Open-minded, rational in-depth explorations of phenomena/problem to be examined.

4. To measure or classify but no mention of any rigour in process.

5. Other answers

8. Don't know

9. Refusal/NA 
For the knowledge scale this was recoded: $1-4=$ correct $(1)$, all other answers $=$ incorrect $(0)$.

2. Suppose a drug used to treat high blood pressure is suspected of not working well. On this card are three different ways scientists might use to investigate this problem. Which one do you think scientists would be most likely to use?

1. Talk to patients to get their opinions

2. Use their knowledge of medicine to decide how good the drug is

3. Give the drug to some patients but not to others. Then compare what happens in each group.

8. Don't know

9. Refusal/NA

For the knowledge scale this was recoded: $3=$ correct $(1)$, all other answers $=$ incorrect $(0)$.

3. Doctors tell a couple that their genetic make-up means that they've got a one in four chance of having a child with an inherited illness. Does this mean that ?...or

1. If they have only three children, none will have the illness?...or

2. If their first child has the illness, the next three will not ?...or

3. Each of the couple's children has the same risk of suffering from the illness ?...or

4. If their first three children are healthy, the fourth will have the illness?

For the knowledge scale this was recoded: $3=$ correct $(1)$, all other answers $=$ incorrect (0).

Here is a quick quiz. For each thing I say, tell me if it is true or false. If you don't know, say so and we will skip to the next.

4. The centre of the earth is very hot. 
5. Lasers work by focusing sound waves.

6. Antibiotics kill viruses as well as bacteria.

For the knowledge scale these were recoded: correct (1), all other answers (0).

7. Does the...

1. earth go round the sun

2. or the sun go around the earth?

8. Don't know

9. Refusal/DK

For the knowledge scale this was recoded: $1=$ correct $(1)$, all other answers = incorrect (0).

8. Here is a statement about which people disagree.

Human beings as we know them today developed from earlier species of animals would you say this was...

1. Definitely true

2. Probably true

3. Probably untrue

4. or, definitely untrue

8. Don't know

9. Refusal/NA

For the knowledge scale this was recoded: $1=$ correct $(1)$, all other answers = incorrect (0). 
9. When scientists use the term DNA, do you think it is to do with the study of...
1 ...stars
2 rocks,
3 living things,
4 or computers?
8 Don't know
9 Refusal/NA

For the knowledge scale this was recoded: $3=$ correct (1), all other answers $=$ incorrect (0).

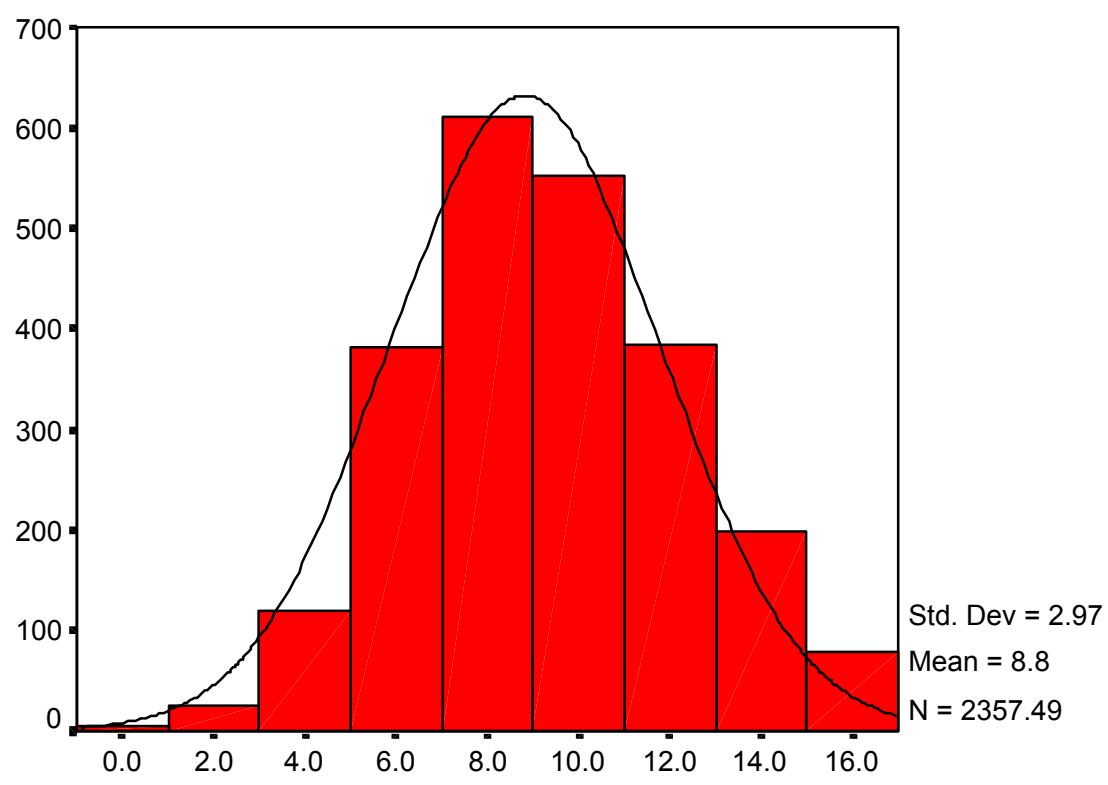

TOTATT

Cases weighted by WTFACTOR

Figure A1 Histogram of Attitude Toward Science Scale 


\section{Notes}

1 An earlier version of this article was presented at the World Association of Public Opinion Research (WAPOR) Annual Conference, Date, Rome, Italy.

2 We use this term to denote this perspective because, in this view, knowledge of science is seen not as an abstract canon of 'facts' but as sets of understandings within varying practical and social contexts. The effect of one form of understanding on attitude will, in this view, be contextualised by other areas of knowledge.

3 We are here interpreting Einsiedel's use of 'interactive science model' as being equivalent or nearly equivalent to what we refer to as the contextualist perspective.

4 They include as 'knowledge' items, statements such as 'The reward of scientific research is recognition rather than money' and 'For the industrialized countries investment in science is a top priority' which we consider express unverifiable beliefs that are more indicative of attitudes.

5 The survey uses a multi-stage sampling design and is representative of the UK adult population. It was carried out by Social and Community Planning Research and achieved an overall response rate of 65 per cent.

6 While this coefficient is well below the traditional cut-off criterion for scale reliability of 0.7 , more sophisticated scale assessment using Confirmatory Factor Analysis (CFA) suggests a one factor model fits the data extremely well $(X 2=0.2 ; d f=1 ; p=0.647)$, with all 4 indicators contributing significantly $(p<0.001)$ to the common factor variance.

7 The predicted scores assume values of zero on all other independent variables in the model.

8 However, we point such readers in the direction of King, Keohane and Verba (1994) and Goldthorpe (2000) for excellent expositions in this regard. 